\title{
Health providers react to Bill C-14
}

$\mathrm{P}$ hysician and nursing organizations have cautiously welcomed the federal government's proposed assisted death legislation, but concerns remain about the criteria for access to the service and protections for conscientious objectors.

The proposed Bill C-14 restricts assisted death to mentally competent adults who have a serious and incurable illness, disease or disability, and for whom natural death is likely in the forseeable future. It does not address more controversial issues, such as whether assisted death should be available to children or people with mental illnesses.

"It meets our call for a very measured and cautionary approach, particularly with the initial legislation," says Dr. Jeff Blackmer, vice president of medical professionalism for the Canadian Medical Association (CMA). "In other jurisdictions where, for example, assisted dying is available for patients with a mental illness or for mature minors, they started with legislation that did not include those considerations and added them later upon further study."

Spokespeople for the College of Family Physicians of Canada and the Canadian Nurses Association have likewise expressed satisfaction with the federal government's "prudent" response.

Dr. Kevin Imrie, president of the Royal College of Physicians and Surgeons of Canada, agrees that the legislation is a good first step to "provide clarity and consistency across the country."

"The most important thing is that there was a desperate need for a legislative solution."

The Supreme Court gave Parliament until June 6 to come up with a new law. Bill C-14 had its first reading in the House on April 14, second reading on April 20, and will be debated for two days when Parliament reconvenes on May 2.

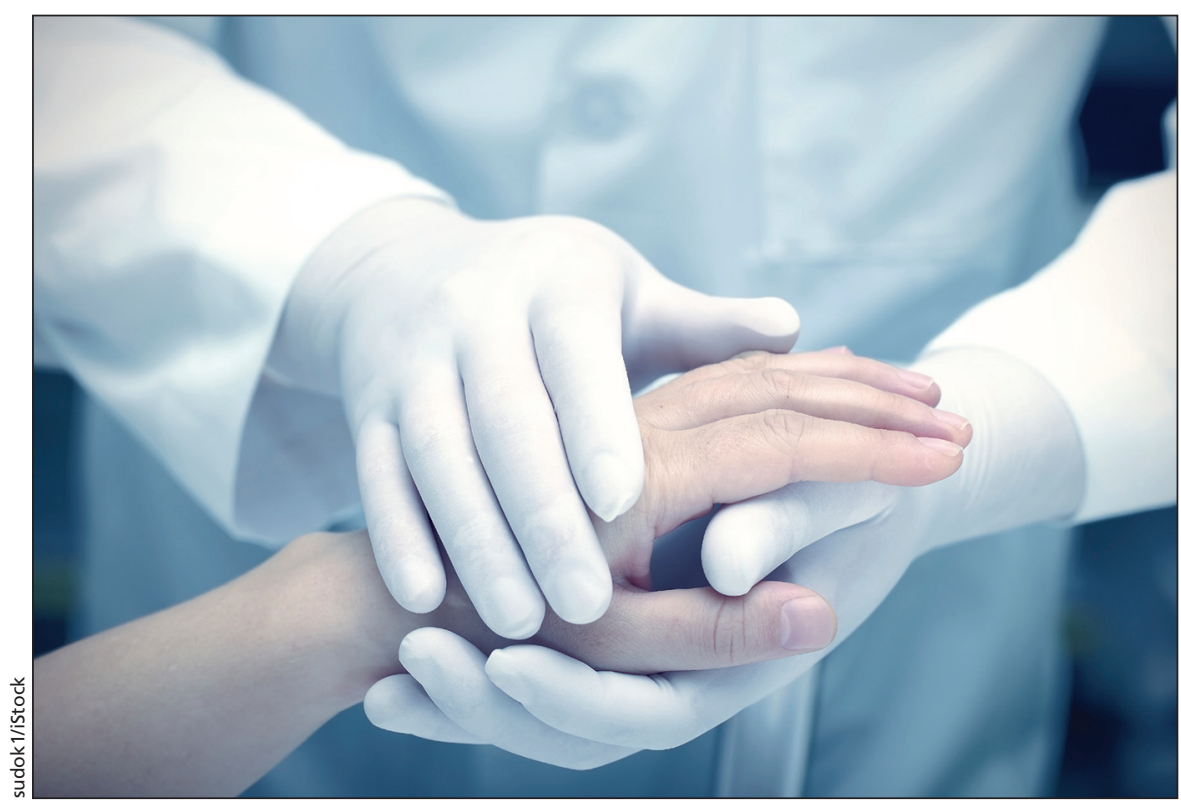

Proposed federal rules would limit assisted death to the terminally ill.

\section{Prudent protections}

According to Blackmer, the bill's key strengths include safeguards such as requiring a waiting period and sign-off from two physicians or nurse practitioners before granting a patient's request for assistance to die.

Nursing representatives also commend the decision to allow nurse practitioners to provide assisted death. "More than three million Canadians have a nurse practitioner as their sole primary care provider," so this exemption is necessary for fair access, says Carolyn Pullen, director of policy, advocacy and strategy for the Canadian Nurses Association (CNA).

Pullen also welcomes commitments in the preamble of the legislation to strengthen palliative care. "While it is extremely important to get this bill right, nurses feel that first and foremost Canada needs an overarching palliative care strategy," says Pullen. "Approximately two to three percent of Canadians may request medical assistance in dying, but $100 \%$ of Canadians may need some form of palliative care."

According to Sharon Baxter, executive director of the Canadian Hospice
Palliative Care Association, "it would be unfortunate if individuals ... choose to end their lives only because they were not given proper access to pain and symptom management."

Baxter also hopes provinces and territories will follow Quebec's lead to allow hospices to opt out of providing assisted death, a point the proposed federal law doesn't address. "Hospice palliative care must be recognized as a parallel issue that is separate from medical assistance in dying," she argues.

\section{Vague eligibility}

However, opinions vary on the eligibility criteria for accessing assisted death, particularly when it comes to the requirements that eligible patients have an "incurable" condition, as well as a "reasonably foreseeable" natural death.

"The criteria are a little bit on the vague side," says Dr. Francine Lemire, chief executive officer of the College of Family Physicians of Canada (CFPC). "In terms of a terminal condition ... what kind of timeline does that define?"

Some fear that requiring a condition to be "incurable" may place an onus on 
patients to exhaust all possible treatments in order to be eligible for assisted death. "I think we might be more comfortable if that particular expression was not present," says Pullen.

Others argue that federal legislation shouldn't be expected to define all aspects of a medical act. "You will never be able to find language that addresses all of the eventualities and the best you can do in a scenario like this is trying to find language that gives enough guidance to be helpful for physicians but still allows for the leeway in terms of clinical judgment," Blackmer says.

Imrie agrees, noting that, "the ultimate oversight will rest with the medical regulatory authorities."

\section{Missing conscience safeguards}

Also troubling for some providers is Bill C-14's silence on protections for those who refuse to provide or refer patients for assisted death.

"It appears as though the provinces are not going to legislate on this either, and then we'll be in a position where we'll constantly have to fight for our conscience rights," says Larry Worthen, executive director of the Christian Medical and Dental Society of Canada, a group that represents some 5000 Catholic and evangelical physicians. Worthen cites the ongoing legal tussle between his group and the College of Physicians and Surgeons of Ontario over mandatory referral for abortion as an example of the challenges that can arise when specific conscience safeguards are absent.

For some Christians, Jews and Muslims, even referring a patient for assisted death would be "formal cooperation in an immoral act," Worthen explains. "This is a request that goes far beyond what is appropriate for any government or regulator to demand."

Other groups share Worthen's concerns, but emphasize the need to balance protections for providers with access for patients. Issues of conscience "need to be clarified so that patients and families don't fall through the cracks," says Vicki McKenna, first vice-president of the Ontario Nurses' Association.

Pullen argues that the current protections for conscientious objection are usually sufficient. "Medical assistance in dying is not an emergency procedure and employers already have significant structures, policies and processes in place that allow nurses to conscientiously object and be replaced in a timely manner."

CMA, for its part, is urging the creation of a central referral system for assisted death in order to strengthen protections for both providers and patients. "The government has committed to work with the provinces to develop the system," Blackmer notes. "That will really get around the issue of mandatory referrals because patients can access the system directly to connect with a willing provider."

A central referral system will also prevent situations such as the recent case of an Alberta woman who had to leave the province for medical aid in dying, even though there were "hundreds of doctors in Calgary who would have been willing to help but no system to make that connection," says Blackmer. "As personally involved as I have been in this issue, even I don't know where to refer someone."

\section{Further training needed}

The CMA, Royal College, CFPC and CNA are all developing resources to prepare physicians and nurses to talk about and provide assisted death. CMA has taken the lead on continuing professional development for physicians and will offer online training in June, as well as an "intense in-person course" in Vancouver this fall for physicians who want more detail on actually providing assisted death.

Although some health facilities are working on policies and procedures to guide implementation of the service, many are waiting for further instructions from health authorities and the regulatory colleges once assisted death becomes legal.

"Some have done nothing yet," says McKenna. "Big organizations that have policy and procedure people, they'll be all over it, but we also have organizations that aren't as informed or don't have the same capacity."

Blackmer says it's unrealistic to expect perfect readiness from government, regulators or health providers by the June 6 deadline. "There needs to be some degree of patience initially and recognition that it will take time to sort out the bugs in the system," he explains. "This is the first time in centuries that the medical profession is being asked to take on a completely new role, and that will take time." Lauren Vogel, CMAJ

CMAJ 2016. DOI:10.1503/cmaj.109-5271 